\title{
REPRODUCIBILITY OF BLOOD PRESSURE DIPPING: RELATION TO DAY-TO-DAY VARIABILITY IN SLEEP QUALITY
}

\author{
Alan L. Hinderliter, MD'1 , Faye S. Routledge, RN, $\mathrm{PhD}^{2,3}$, James A. Blumenthal, $\mathrm{PhD}^{2}$, Gary \\ Koch, PhD ${ }^{1}$, Michael A. Hussey, MS ${ }^{1}$, William K. Wohlgemuth, $\mathrm{PhD}^{4}$, and Andrew \\ Sherwood, PhD $^{2}$ \\ ${ }^{1}$ University of North Carolina at Chapel Hill, Chapel Hill, NC \\ 2Duke University Medical Center, Durham, NC \\ ${ }^{3}$ Nell Hodgson Woodruff School of Nursing, Emory University, Atlanta, GA \\ ${ }^{4}$ Psychology Service, Miami VA Healthcare System, Miami, FI
}

\begin{abstract}
Background-Previous studies of the reproducibility of blood pressure (BP) dipping have yielded inconsistent results. Few have examined factors that may influence dayto-day differences in dipping.

Methods and Results-Ambulatory BP monitoring was performed on three occasions, approximately one week apart, in 115 untreated adult subjects with elevated clinic BPs. The mean \pm SD BP dip was $18 \pm 7 / 15 \pm 5 \mathrm{mmHg}$ (sleep/awake BP ratio $=0.87 \pm 0.05 / 0.82 \pm 0.06$ ), with a median (interquartile range) day-to-day variation of $5.2(3.1-8.1) / 4.3(2.8-5.6) \mathrm{mmHg}$. There was no decrease in variability with successive measurements. The reproducibility coefficient (5.6 [95\% CI $5.1,6.1] \mathrm{mmHg})$ was greater and the intraclass correlation coefficient $(0.53$ [95\% CI 0.42, 0.63]) was smaller for the systolic dip than for 24-hour or awake systolic BPs, suggesting greater daytoday variability in dipping. Variability in systolic dipping was greater in subjects with higher awake BP, but was not related to age, gender, race, or body mass index. Within individuals, dayto-day variations in dipping were related to variations in the fragmentation index ( $p<0.001)$, a measure of sleep quality.
\end{abstract}

Conclusions-Although mean 24-hour and awake BPs were relatively stable over repeated monitoring days, our study confirms substantial variability in BP dipping. Day-to-day differences in dipping are related to sleep quality.

\section{Keywords}

ambulatory blood pressure monitoring

\footnotetext{
(C) 2013 American Society of Hypertension. Published by Elsevier Inc. All rights reserved.

Corresponding Author: Alan L. Hinderliter, MD, Division of Cardiology, CB \#7075, Burnett Womack Building, University of North Carolina at Chapel Hill, Chapel Hill, NC 27599-7075, Tel: (919)-843-5447; Fax: (919) 966-7143; , hinderli@ med.unc.edu.

Publisher's Disclaimer: This is a PDF file of an unedited manuscript that has been accepted for publication. As a service to our customers we are providing this early version of the manuscript. The manuscript will undergo copyediting, typesetting, and review of the resulting proof before it is published in its final citable form. Please note that during the production process errors may be discovered which could affect the content, and all legal disclaimers that apply to the journal pertain.

Conflict of Interest/Disclosure Statement: None
} 


\section{INTRODUCTION}

Measurement of blood pressure (BP) throughout the day using ambulatory BP monitoring (ABPM) permits quantification of the "average" BP over 24 hours, as well as an assessment of the diurnal pattern of BP variation. Multiple studies have demonstrated that average ambulatory BP is more predictive of end-organ damage and of adverse cardiovascular events than is clinic BP. (1-11) Similarly, the diurnal pattern of BP variation may be of prognostic significance, with non-dippers - i.e., individuals with a small or no fall in BP during sleep - at increased risk of adverse cardiovascular outcomes. $(1,2,4,5,8,10,12-19)$

One factor that has limited enthusiasm for incorporating measurement of the BP dip into the clinical evaluation and management of patients is concern over the reproducibility of this measurement. Previous studies evaluating the day-to-day consistency of the diurnal BP profile have yielded differing results that have been influenced by factors such as the age, co-existing medical conditions, and treatment of the subjects, as well as the time interval between successive measurements. $(17,20-27)$ Some have focused on the classification of patients as dippers or non-dippers based on defined partition values, an approach in which individual subjects may have discordant results from one monitoring session to the next despite quantitatively small differences in the BP fall during sleep. Few have examined the impact of demographic characteristics or of day-to-day variation in sleep quality or daytime activity levels on the reproducibility of the BP dip.

In this study, we quantitatively examined the reproducibility of the BP dip and other measures of ambulatory BP in a cohort of generally healthy subjects with elevated clinic BPs who underwent ABPM on three occasions. We also assessed the influences of demographic features, awake BP levels, sleep duration and quality, and awake physical activity levels on day-to-day variations in BP dipping.

\section{METHODS}

\section{Subjects}

Participants included generally healthy men and women between the ages of 40 and 60 years who had never been treated with anti-hypertensive medications and who had screening systolic BPs of 130-159 mmHg and/or diastolic BPs of 85-99 mmHg. Individuals at high risk of sleep apnea, based on clinical history or on screening using the Duke Structured Interview for Sleep Disorders (28) and Berlin Sleep Apnea Index (29), were excluded. Other exclusion criteria have been described elsewhere in detail (30), and included diabetes, atrial fibrillation, chronic kidney disease, use of oral contraceptives or hormone replacement therapy, or incomplete data on any one of the three ABPM sessions. Participants were recruited by paid advertisements. The study was approved by the Institutional Review Board at Duke University Medical Center, Durham, NC, and written informed consent was obtained from all participants prior to their participation.

\section{Screening BP}

Screening BPs were acquired on three separate visits to the research laboratory, each approximately one week apart. At each visit, with the subject seated in a quiet, temperature controlled room, four seated BP measurements were acquired by a trained technician using a mercury sphygmomanometer. The BP for each visit was calculated as the mean of the last three readings, and eligibility for the study was based upon the average of the BP values from each of the three visits. 


\section{Demographic assessments}

Data on age, gender, ethnicity, height, and weight were acquired on screening visits. Body mass index (BMI) was calculated as weight $(\mathrm{kg}) /$ height $(\mathrm{m})^{2}$.

\section{ABPM}

ABPM was performed using an OSCAR II monitor (Suntech Medical, Inc., Raleigh, NC), an oscillometric device that has been validated for accuracy. $(31,32)$ Twenty-four hour records were acquired on three typical work days, separated by approximately one week. The monitor was programmed to make BP measurements every 20 minutes during the day and every 30 minutes at night. A minimum of 6 valid measurements were required during the sleep period, and 20 valid measurements were required during the waking period.

\section{Assessment of sleep duration and quality and of daytime activity levels}

Waking and sleep periods were defined by self-report diaries and confirmed by actigraphy. The actigraphy monitor (Mini-Mitter, Inc., Sunriver, OR) is worn around the wrist and contains a calibrated accelerometer that samples movement and activity at a rate of 32/sec. The actigraphy-based fragmentation index, a measure of the restlessness of sleep, was defined as the sum of 2 percentages: the percentage of the sleep period spent moving, and the percentage of the number of immobile phases that were $\leq 1$ minute long. Sleep efficiency was defined as the percent of time asleep during the time in bed. Previous studies have demonstrated that actigraphic measures reflect sleep quality as assessed by polysomnography. $(33,34)$ Daytime activity was expressed as the average activity counts/ minute during the waking period.

\section{Data analysis}

All analyses were performed using SAS statistical software, version 9.3 (SAS, Cary, NC).

Waking and sleep systolic BPs for each individual were computed as the averaged awake and sleep BPs for each of the three monitoring sessions. The systolic BP dip for each session was derived by subtracting mean sleep systolic BP from mean awake systolic BP, and the systolic sleep/awake BP ratio was calculated as mean systolic sleep BP/mean systolic awake BP. The day-to-day variability for each measure of systolic BP and systolic BP dipping was quantified for each subject as the average absolute variation (the mean absolute difference in values between sessions 1 and 2, sessions 2 and 3, and sessions 3 and 1). Analogous calculations were made for diastolic BPs. For descriptive purposes, a dipper was defined by systolic and diastolic sleep/awake BP ratios $\leq 0.90$, while subjects with either a systolic or diastolic sleep/awake BP ratio of $>0.90$ were classified as nondippers.

The day-to-day variability in each measure of sleep duration and quality and of daytime activity levels was quantified as the average absolute variation over the 3 sessions.

Descriptive statistics were summarized as mean $\pm \mathrm{SD}$ for continuous demographic variables and for measures of BP, sleep, and activity; as median (interquartile range) for measures of day-to-day variability; and as number (\%) of subjects for categorical variables.

Differences in mean BP measurements (screening, awake, sleep, dip, and sleep/awake ratio) on sessions 1, 2, and 3 were examined using repeated measures analysis of variance.

The reproducibility of the systolic BP dip between sessions 1 and 2, 2 and 3, and 1 and 3 were illustrated by Bland Altman plots, and plots were also constructed to illustrate the reproducibility of systolic BP dip in comparison to other measure of systolic BP between sessions 1 and 2. Utilizing the data from all 3 sessions, the reproducibility coefficient of 
each measure of BP was defined as the within-subject standard deviation $\left(\mathrm{S}_{\mathrm{w}}\right)$ derived from a one-way analysis of variance. The intraclass correlation coefficient, an index describing the proportion of the total variance in BP measurements that is due to "true" differences between subjects, was calculated from the between-subject and error variances of the oneway analysis of variance $\left(\mathrm{R}=\sigma^{2}\right.$ subjects $/\left(\sigma_{\text {subjects }}^{2}+\sigma_{\text {error }}^{2}\right)=\left(\mathrm{MS}_{\text {subjects }}-\mathrm{MS}_{\text {error }}\right) /$ $\left(\mathrm{MS}_{\text {subjects }}+2 \mathrm{MS}_{\text {error }}\right)$, where $\mathrm{MS}=$ mean square). The levels of agreement between sessions 1 and 2, 2 and 3, and 1 and 3 in classification of subjects as dippers or nondippers were quantified using the kappa statistic.

The relationships of awake BP and continuous demographic variables (age and BMI) to the average absolute variation in the BP dip were examined with Spearman's correlations. Gender and race (classified as white or non-white) differences in the variation in BP dipping were assessed by the Wilcoxon rank sum test.

Mixed models were utilized to examine the impact of within-subject differences in sleep duration, sleep quality (fragmentation index and sleep efficiency), and daytime physical activity (quantified as the average activity counts/minute) on day-to-day differences in BP dipping. The mixed models were constructed to recognize that ambulatory BP data have two components: one due to the sampling of subjects and the other due to the sampling of repeated measurements within subjects. In order to estimate the impact of intra-individual day-to-day differences (rather than inter-individual differences) in sleep duration and quality and in daytime activity, average values across the 3 sessions for sleep duration, sleep quality measures, and activity counts/minute for each subject were included in the models.

\section{RESULTS}

The demographic characteristics of the 115 study participants are summarized in Table 1. The average age was $46 \pm 9$ years; $43 \%$ of the subjects were female. There were $63(55 \%)$ whites, 42 (37\%) African Americans, and 10 (9\%) subjects of other ethnicities. The mean awake BP was $136 \pm 11 / 84 \pm 8 \mathrm{mmHg}$, with a dip of $18 \pm 7 / 15 \pm 5 \mathrm{mmHg}$. The systolic and diastolic sleep/awake BP ratios were $0.87 \pm 0.05$ and $0.82 \pm 0.06$, respectively. The percentages of subjects qualifying as dippers were $65 \%, 66 \%$, and $70 \%$, respectively, on the three sessions (data not shown). Measures of sleep duration and quality and of daytime activity levels are shown in Table 2; the typical sleep period duration was 7.6 \pm 1.0 hours per night.

The reproducibility of the systolic BP dip between sessions 1 and 2, 2 and 3, and 1 and 3 is illustrated by Bland Altman plots in Figure 1. There was no decrease in the withinindividual day-to-day variability of the BP dip with successive measurements. The greater variability in screening BP, sleep BP, and BP dip than in awake BP is shown in Figure 2. A shift on successive measurements was noted only for screening BPs, which averaged $142 \pm 9$ $\mathrm{mmHg}$ on visit $1,140 \pm 8 \mathrm{mmHg}$ on visit 2 , and $138 \pm 8 \mathrm{mmHg}$ on visit 3 ( $\mathrm{p}<0.0001$ for difference between sessions); mean awake and sleep ambulatory BPs and the BP dip remained stable across monitoring sessions. Similar findings were noted when measures of diastolic BP were examined (data not shown).

The median (interquartile range) absolute day-to-day variation in systolic/diastolic BP dip was $5.2(3.1-8.1) / 4.3(2.8-5.6)$. The absolute day-to-day variation, reproducibility coefficient (within-subject standard deviation), and intraclass correlation coefficient (proportion of the total variance in BP due to "true" differences between subjects) for each measure of systolic $\mathrm{BP}$ are shown in Table 3. The lowest intraclass correlations were for the BP dip and the sleep/awake BP ratio, reflecting the considerable day-today variability in these measurements and the relatively constricted range of values. Similarly, the diastolic BP dip 
and sleep/awake BP ratio had the lowest intraclass correlations $(0.48,95 \% \mathrm{CI} 0.37,0.58$; and $0.54,95 \%$ CI $0.43,0.63$, respectively) amongst measures of diastolic BP (data not shown). Of note, average awake BP was more reproducible than either sleep BP or screening BP.

There was agreement between sessions 1 and 2 in categorizing individuals as dippers or nondippers in $74 \%$ of subjects, with a kappa coefficient of 0.41 ; agreement between sessions 2 and 3 in $76 \%$ of subjects, with a kappa of 0.43 ; and agreement between sessions 1 and 3 in $70 \%$ of subjects, with a kappa of 0.31 .

The average absolute variation of systolic BP dipping was significantly correlated with awake systolic BP $(r=0.27, p=0.003)$. Subjects with a greater BMI tended to exhibit more day-to-day variability in systolic dipping $(r=0.16, p=0.077)$, but this tendency did not achieve statistical significance. There was no apparent relationship of age to the magnitude of systolic dipping variability $(\mathrm{r}=-0.06, \mathrm{p}=0.496)$. There were no differences in systolic $\mathrm{BP}$ dipping variability by gender $(\mathrm{p}=0.446)$ or race $(\mathrm{p}=0.954)$.

The relationships of sleep duration and quality and awake physical activity to intraindividual day-to-day differences in systolic BP dip were examined in the mixed models shown in Table 4. Day-to-day measures of sleep fragmentation index were predictive of the systolic BP dip $(p=0.001)$. Sleep efficiency also tended to predict the day-to-day systolic BP dip, but this relationship did not achieve statistical significance $(\mathrm{p}=0.096)$. In contrast, neither sleep period duration nor awake physical activity was related to day-to-day differences in systolic BP dipping. Day-to-day measures of fragmentation index were also related to the systolic sleep/awake BP ratio $(\mathrm{p}=0.003)$ and diastolic BP dip and sleep/awake $\mathrm{BP}$ ratio $(\mathrm{p}=0.017$ and $\mathrm{p}=0.016$, respectively; data not shown).

To illustrate the influence of within-subject day-to-day variability in sleep quality on systolic BP dipping variability, we compared subjects with high variability in fragmentation index (in the highest quartile for absolute day-to-day variation in fragmentation index) to those with low fragmentation index variability (in the lowest quartile for absolute variation). The absolute day-to-day variations in both systolic BP dip (6.7 [5.0-9.5] vs 4.1 [3.0-7.0] $\mathrm{mmHg}, \mathrm{p}=0.021)$ and sleep/awake BP ratio (0.051 [0.023-0.057] vs 0.031 [0.023-0.047], $\mathrm{p}$ $=0.031$ ) were significantly greater in subjects with greater variability in sleep quality.

\section{DISCUSSION}

Our study confirms previous research suggesting that there is substantial day-today variability in BP dipping. In our cohort of untreated middle-aged men and women with high normal or mildly elevated BPs, the systolic BP dip was less reproducible than average 24hour or awake ambulatory systolic BP, and varied by a median of 5.2 (interquartile range 3.1-8.1) $\mathrm{mmHg}$ from one measurement to the next. The magnitude of the variability in systolic BP dipping was greater in subjects with higher levels of awake BP. In individual subjects, the day-to-day differences in systolic BP dip were related to sleep quality, but not to sleep period duration or to the level of physical activity while awake.

Many of the previous studies evaluating the reproducibility of the diurnal BP profile have examined the reliability of ABPM in classifying individuals as dippers or non-dippers based on a specified partition value (generally a $10 \%$ or greater fall in BP during sleep hours). Cuspidi, et al (35), for example, studied short term reproducibility of the circadian BP profile in 619 never-treated hypertensive patients by performing 24-hour ABPM twice in four weeks. A total of 407 of the 619 subjects were categorized as "dippers" during the first monitored session, but $24 \%$ changed classification on repeat monitoring. The variability in BP dipping was not predicted by age or gender. Omboni, et al (36) reported that 
approximately $40 \%$ of the hypertensive patients enrolled in SAMPLE (Studies on Ambulatory Monitoring of Pressure and Lisinopril Evaluation) changed dipping pattern when ABPM was repeated after one year. In a report from the Spanish ambulatory blood pressure monitoring registry, Hernandez del Rey, et al (20) examined the reproducibility of the circadian BP profile between the first and second 24-hour periods in hypertensive patients who underwent monitoring for 48 hours. Although the percentages of patients categorized as dippers were similar in the two periods (47\% on the first day, $50 \%$ on the second day), $24 \%$ changed classification.

When the reproducibility of dipping is based on dichotomizing subjects as dippers or nondippers, even small changes from one monitoring session to the next may result in a change in classification and lead to the conclusion that reproducibility is poor. Few studies have examined the reproducibility of the diurnal BP profile expressing dipping as a continuous variable. McGowan, et al (37) analyzed nocturnal BP dipping in a retrospective examination of a sample of 512 never-treated patients with two ABPM assessments $29 \pm 19$ months apart. Consistent with prior studies, $24 \%$ of patients changed systolic BP dipping status from one session to the next. The mean nocturnal systolic BP dip was $14 \pm 5 \%$. The median absolute difference in systolic BP dip between sessions was 3.8\%, with an intraclass correlation of 0.60 .

Our study extends the findings of McGowan, et al (37) by examining the short term reproducibility of dipping over three sessions in a more controlled setting, and by examining demographic and behavioral characteristics that may impact reproducibility. The magnitude of the variation in BP dip observed in our subjects was similar to that described by McGowan, et al (37) and did not diminish with the third monitoring session. The variability in BP dipping was not significantly related to age, gender, race, or body mass index. However, day-to-day differences in sleep quality, as measured by the actigraphy-based fragmentation index, had a major influence on the systolic BP dip.

We are not aware of previous studies that have rigorously examined the influences of dayto-day differences in sleep quality on intra-individual variability in BP dipping. Manning, et al (24) noted that self reported poor sleep quality was associated with an attenuated systolic BP dip, but whether day-to-day differences in sleep quality contributed to the lack of reproducibility was not specifically analyzed. A previous analysis of our subject cohort established sleep quality as an independent predictor of between-individual differences in BP dipping. (30) When the BP dip was calculated as the difference between awake and sleep BPs averaged over the three sessions, blunted systolic BP dipping was associated with poor sleep quality as well as a greater body mass index and a smaller fall in sleep period sympathetic nervous system activity. These three factors contributed to an attenuated fall in sleep systolic BP observed in African Americans. Similarly, in a group of 186 participants in the sleep SCORE study, poor sleep quality as indicated by a greater sleep fragmentation index was associated with higher sleep/awake systolic blood pressure ratios (i.e., with a smaller systolic BP dip) in both normotensive and hypertensive individuals. (38)

Although the focus of this report is on BP dipping, our study provides insights into the reproducibility of other measure of BP. Mean 24-hour, awake, and sleep BPs for the group were consistent across the 3 monitoring sessions. This finding is in contrast to some previous studies that have described an "ABPM effect" with higher BP on the initial session, presumably due to the novelty of wearing a device for the first time. $(39,40)$ The average research clinic BP decreased over successive visits, however. Even though group averages for sleep BP and BP dip were consistent over the 3 monitoring sessions, day-to-day variability was greater for these measures than average awake BP, as has been described by other investigators. $(17,21,27)$ This may reflect, to some degree, the smaller number of BP's 
sampled during sleep. Despite careful attention to measurement technique, the day-to-day variability in research clinic BP was greater than for awake ambulatory BP.

Strengths of our study include the focus on generally healthy, middle-aged subjects with clinic BPs that averaged about 140/90 mm Hg - individuals in whom ABPM data may prove valuable in diagnosing hypertension and guiding therapy. Our estimates of variability may not apply, however, to older individuals or to patients with higher BPs or treated hypertension. In addition, our study was conducted in subjects who volunteered for an ABPM monitoring research protocol and were tolerant of repeated monitoring sessions; BP measurements may not be as reliable in less selected patients who undergo monitoring as part of a clinical evaluation. Lastly, the cross-sectional design of our study limits inferences regarding cause-and-effect relationships between clinical characteristics, behaviors, and BP variability.

ABPM is a valuable tool for estimating an individual's "true" BP and is more accurate than clinic BP in defining cardiovascular risk. Moreover, a recent analysis suggests that ABPM may be cost-effective in identifying patients who would benefit from antihypertensive therapy. (41) These observations led to the recent recommendation by the United Kingdom's National Institute for Health and Clinical Excellence (NICE) that ABPM should be routinely employed in the evaluation of untreated patients with elevated clinic BP. (42) Additional research is needed to clarify the physiologic basis and prognostic significance of BP dipping, and to further characterize the factors - including poor sleep quality -- that may contribute to the day-to-day variability in this measurement. Our findings support the NICE recommendation to use average awake $\mathrm{BP}$ in diagnosing hypertension in a patient who has a single assessment of ambulatory BP. In view of the considerable variability in the diurnal pattern of BP, repeated ABPM sessions may be required to confidently estimate an individual patient's BP dip.

\section{Acknowledgments}

We thank Julie Bower, Amy Franklin, and Angela Kirby for their work in supporting the conduct of this study.

This study was supported by Grant HL072390 from the National Heart, Lung, and Blood Institute, National Institutes of Health, Bethesda, MD, and grant M01-RR-30 from the General Clinical Research Center program, National Center for Research Resources, National Institutes of Health.

\section{References}

1. Verdecchia P, Porcellati C, Schillaci G, Borgioni C, Ciucci A, Battistelli M, et al. Ambulatory blood pressure. An independent predictor of prognosis in essential hypertension. Hypertension. 1994 Dec; 24(6):793-801. [PubMed: 7995639]

2. Clement DL, De Buyzere ML, De Bacquer DA, de Leeuw PW, Duprez DA, Fagard RH, et al. Prognostic value of ambulatory blood-pressure recordings in patients with treated hypertension. $\mathrm{N}$ Engl J Med. 2003 Jun 12; 348(24):2407-2415. [PubMed: 12802026]

3. Bjorklund K, Lind L, Zethelius B, Berglund L, Lithell H. Prognostic significance of 24-h ambulatory blood pressure characteristics for cardiovascular morbidity in a population of elderly men. J Hypertens. 2004 Sep; 22(9):1691-1697. [PubMed: 15311096]

4. Hansen TW, Jeppesen J, Rasmussen S, Ibsen H, Torp-Pedersen C. Ambulatory blood pressure and mortality: a population-based study. Hypertension. 2005 Apr; 45(4):499-504. [PubMed: 15753229]

5. Dolan E, Stanton A, Thijs L, Hinedi K, Atkins N, McClory S, et al. Superiority of ambulatory over clinic blood pressure measurement in predicting mortality: the Dublin outcome study. Hypertension. 2005 Jul; 46(1):156-161. [PubMed: 15939805]

6. Perloff D, Sokolow M, Cowan R. The prognostic value of ambulatory blood pressures. JAMA. 1983 May 27; 249(20):2792-2798. [PubMed: 6842787] 
7. Ohkubo T, Imai Y, Tsuji I, Nagai K, Watanabe N, Minami N, et al. Relation between nocturnal decline in blood pressure and mortality The Ohasama Study. Am J Hypertens. 1997 Nov; 10(11): 1201-1207. [PubMed: 9397237]

8. Kario K, Pickering TG, Matsuo T, Hoshide S, Schwartz JE, Shimada K. Stroke prognosis and abnormal nocturnal blood pressure falls in older hypertensives. Hypertension. 2001 Oct; 38(4):852857. [PubMed: 11641298]

9. Dawes MG, Coats AJ, Juszczak E. Daytime ambulatory systolic blood pressure is more effective at predicting mortality than clinic blood pressure. Blood Press Monit. 2006 Jun; 11(3):111-118. [PubMed: 16702819]

10. Mesquita-Bastos J, Bertoquini S, Polonia J. Cardiovascular prognostic value of ambulatory blood pressure monitoring in a Portuguese hypertensive population followed up for 8.2 years. Blood Press Monit. 2010 Oct; 15(5):240-246. [PubMed: 20616705]

11. Franklin SS, Thijs L, Hansen TW, Li Y, Boggia J, Kikuya M, et al. Significance of white-coat hypertension in older persons with isolated systolic hypertension: a metaanalysis using the International Database on Ambulatory Blood Pressure Monitoring in Relation to Cardiovascular Outcomes population. Hypertension. 2012 Mar; 59(3):564-571. [PubMed: 22252396]

12. O'Brien E, Sheridan J, O'Malley K. Dippers and non-dippers. Lancet. 1988 Aug 13.2(8607):397. [PubMed: 2899801]

13. Ohkubo T, Hozawa A, Yamaguchi J, Kikuya M, Ohmori K, Michimata M, et al. Prognostic significance of the nocturnal decline in blood pressure in individuals with and without high 24-h blood pressure: the Ohasama study. J Hypertens. 2002 Nov; 20(11):2183-2189. [PubMed: 12409956]

14. Mancia G, Facchetti R, Bombelli M, Grassi G, Sega R. Long-term risk of mortality associated with selective and combined elevation in office, home, and ambulatory blood pressure. Hypertension. 2006 May; 47(5):846-853. [PubMed: 16567588]

15. Staessen JA, Thijs L, Fagard R, O'Brien ET, Clement D, de Leeuw PW, et al. Predicting cardiovascular risk using conventional vs ambulatory blood pressure in older patients with systolic hypertension Systolic Hypertension in Europe Trial Investigators. JAMA. 1999 Aug 11; 282(6): 539-546. [PubMed: 10450715]

16. Ben-Dov IZ, Kark JD, Ben-Ishay D, Mekler J, Ben-Arie L, Bursztyn M. Predictors of all-cause mortality in clinical ambulatory monitoring: unique aspects of blood pressure during sleep. Hypertension. 2007 Jun; 49(6):1235-1241. [PubMed: 17389258]

17. Schwartz GL, Turner ST, Moore JH, Sing CF. Effect of time of day on intraindividual variability in ambulatory blood pressure. Am J Hypertens. 2000 Nov; 13(11):1203-1209. [PubMed: 11078181]

18. Fagard RH, Celis H, Thijs L, Staessen JA, Clement DL, De Buyzere ML, et al. Daytime and nighttime blood pressure as predictors of death and cause-specific cardiovascular events in hypertension. Hypertension. 2008 Jan; 51(1):55-61. [PubMed: 18039980]

19. Ingelsson E, Bjorklund-Bodegard K, Lind L, Arnlov J, Sundstrom J. Diurnal blood pressure pattern and risk of congestive heart failure. JAMA. 2006 Jun 28; 295(24):2859-2866. [PubMed: 16804152]

20. Hernandez-del Rey R, Martin-Baranera M, Sobrino J, Gorostidi M, Vinyoles E, Sierra C, et al. Reproducibility of the circadian blood pressure pattern in 24-h versus 48-h recordings: the Spanish Ambulatory Blood Pressure Monitoring Registry. J Hypertens. 2007 Dec; 25(12):2406-2412. [PubMed: 17984661]

21. Palatini P, Mormino P, Canali C, Santonastaso M, De Venuto G, Zanata G, et al. Factors affecting ambulatory blood pressure reproducibility. Results of the HARVEST Trial Hypertension and Ambulatory Recording Venetia Study. Hypertension. 1994 Feb; 23(2):211-216. [PubMed: 8307631]

22. James MA, Fotherby MD, Potter JF. Reproducibility of the circadian systolic blood pressure variation in the elderly. J Hypertens. 1995 Oct; 13(10):1097-1103. [PubMed: 8586801]

23. Mochizuki Y, Okutani M, Donfeng Y, Iwasaki H, Takusagawa M, Kohno I, et al. Limited reproducibility of circadian variation in blood pressure dippers and nondippers. Am J Hypertens. 1998 Apr; 11(4 Pt 1):403-409. [PubMed: 9607377] 
24. Manning G, Rushton L, Donnelly R, Millar-Craig MW. Variability of diurnal changes in ambulatory blood pressure and nocturnal dipping status in untreated hypertensive and normotensive subjects. Am J Hypertens. 2000 Sep; 13(9):1035-1038. [PubMed: 10981556]

25. Chaves H, Campello de Souza FM, Krieger EM. The reproducibility of dipping status: beyond the cutoff points. Blood Press Monit. 2005 Aug; 10(4):201-205. [PubMed: 16077266]

26. Ben-Dov IZ, Ben-Arieh L, Mekler J, Bursztyn M. Blood pressure dipping is reproducible in clinical practice. Blood Press Monit. 2005 Apr; 10(2):79-84. [PubMed: 15812255]

27. Thijs L, Amery A, Clement D, Cox J, de Cort P, Fagard R, et al. Ambulatory blood pressure monitoring in elderly patients with isolated systolic hypertension. J Hypertens. 1992 Jul; 10(7): 693-699. [PubMed: 1321198]

28. Edinger JD, Wyatt JK, Olsen MK, Stechuchak KM, Carney CE, Chiang A, et al. Reliability and validity of the Duke Structured Interview for Sleep Disorders for insomnia screening. Sleep. 2009; 32:0810.

29. Netzer NC, Stoohs RA, Netzer CM, Clark K, Strohl KP. Using the Berlin Questionnaire to identify patients at risk for the sleep apnea syndrome. Ann Intern Med. 1999 Oct 5; 131(7):485-491. [PubMed: 10507956]

30. Sherwood A, Routledge FS, Wohlgemuth WK, Hinderliter AL, Kuhn CM, Blumenthal JA. Blood pressure dipping: ethnicity, sleep quality, and sympathetic nervous system activity. Am J Hypertens. 2011 Sep; 24(9):982-988. [PubMed: 21633397]

31. Goodwin J, Bilous M, Winship S, Finn P, Jones SC. Validation of the Oscar 2 oscillometric 24-h ambulatory blood pressure monitor according to the British Hypertension Society protocol. Blood Press Monit. 2007 Apr; 12(2):113-117. [PubMed: 17353655]

32. Jones SC, Bilous M, Winship S, Finn P, Goodwin J. Validation of the OSCAR 2 oscillometric 24hour ambulatory blood pressure monitor according to the International Protocol for the validation of blood pressure measuring devices. Blood Press Monit. 2004 Aug; 9(4):219-223. [PubMed: 15311149]

33. Morgenthaler T, Alessi C, Friedman L, Owens J, Kapur V, Boehlecke B, et al. Practice parameters for the use of actigraphy in the assessment of sleep and sleep disorders: an update for 2007. Sleep. 2007 Apr; 30(4):519-529. [PubMed: 17520797]

34. Wang D, Wong KK, Dungan GC 2nd, Buchanan PR, Yee BJ, Grunstein RR. The validity of wrist actimetry assessment of sleep with and without sleep apnea. J Clin Sleep Med. 2008 Oct 15; 4(5): 450-455. [PubMed: 18853703]

35. Cuspidi C, Meani S, Valerio C, Sala C, Fusi V, Masaidi M, et al. Reproducibility of dipping/ nondipping pattern in untreated essential hypertensive patients: impact of sex and age. Blood Press Monit. 2007 Apr; 12(2):101-106. [PubMed: 17353653]

36. Omboni S, Parati G, Palatini P, Vanasia A, Muiesan ML, Cuspidi C, et al. Reproducibility and clinical value of nocturnal hypotension: prospective evidence from the SAMPLE study Study on Ambulatory Monitoring of Pressure and Lisinopril Evaluation. J Hypertens. 1998 Jun; 16(6):733738. [PubMed: 9663912]

37. McGowan NJ, Gough K, Padfield PL. Nocturnal dipping is reproducible in the long term. Blood Press Monit. 2009 Oct; 14(5):185-189. [PubMed: 19641455]

38. Matthews KA, Kamarck TW, H Hall M, Strollo PJ, Owens JF, Buysse DJ, et al. Blood pressure dipping and sleep disturbance in African-American and Caucasian men and women. Am J Hypertens. 2008 Jul; 21(7):826-831. [PubMed: 18483473]

39. Calvo C, Hermida RC, Ayala DE, Lopez JE, Fernandez JR, Dominguez MJ, et al. The 'ABPM effect' gradually decreases but does not disappear in successive sessions of ambulatory monitoring. J Hypertens. 2003 Dec; 21(12):2265-2273. [PubMed: 14654746]

40. Hermida RC, Calvo C, Ayala DE, Fernandez JR, Ruilope LM, Lopez JE. Evaluation of the extent and duration of the "ABPM effect" in hypertensive patients. J Am Coll Cardiol. 2002 Aug 21; 40(4):710-717. [PubMed: 12204501]

41. Lovibond K, Jowett S, Barton P, Caulfield M, Heneghan C, Hobbs FD, et al. Costeffectiveness of options for the diagnosis of high blood pressure in primary care: a modelling study. Lancet. 2011 Oct 1; 378(9798):1219-1230. [PubMed: 21868086] 
42. NICE. [Accessed March 30, 2012] Hypertension: The clinical management of primary hypertension in adults CG127. Available at: http://www.nice.org.uk/guidance/CG127/Guidance 

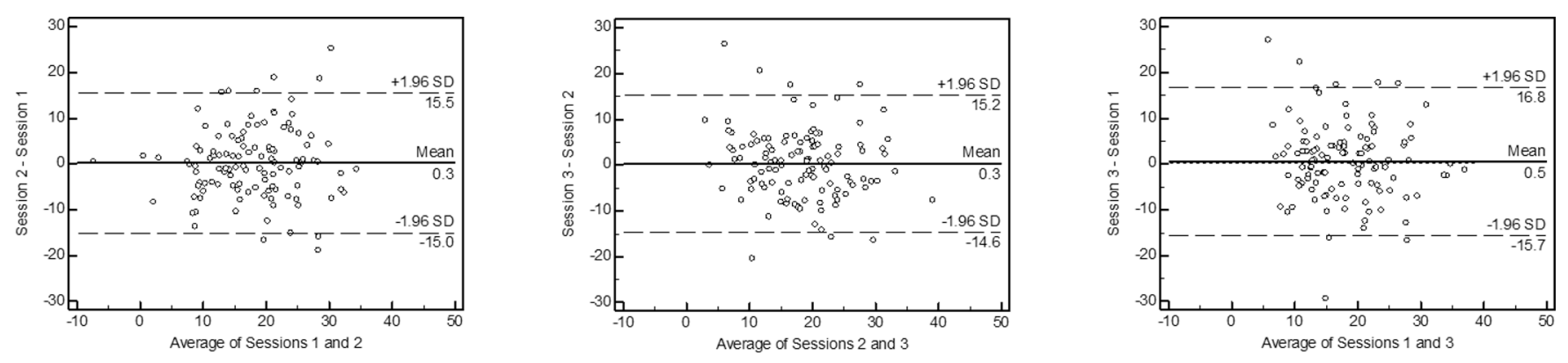

Figure 1.

Bland Altman plots for systolic BP dip comparing sessions 1 and 2, 2 and 3, and 1 and 3. 

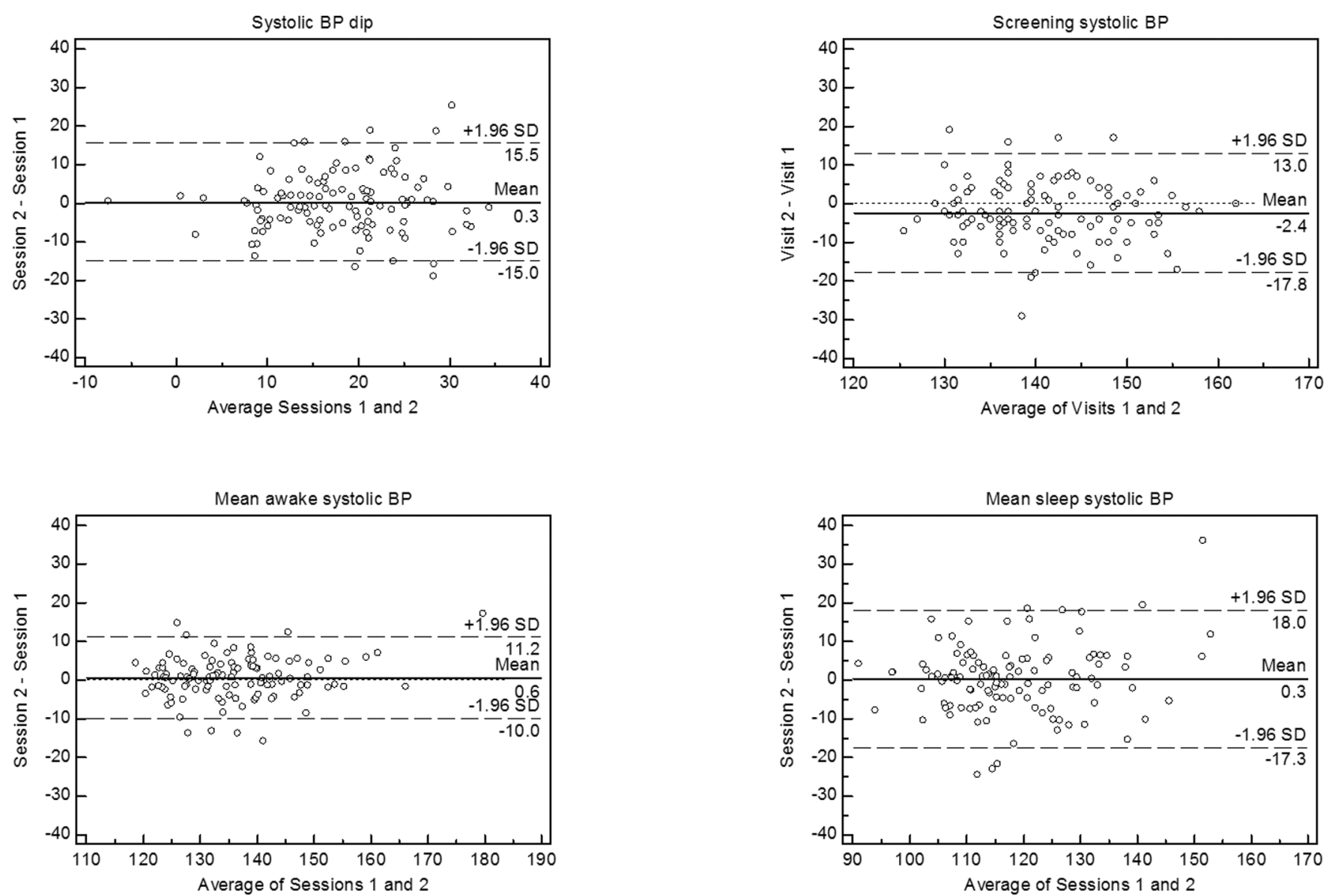

Figure 2.

Bland Altman plots comparing sessions 1 and 2 for systolic BP dip, screening systolic BP, awake systolic BP, and sleep systolic BP.

$\mathrm{BP}=$ blood pressure 


\section{Table 1}

Characteristics of the study cohort

\begin{tabular}{lc}
\hline Characteristic & N (\%) or mean \pm SD \\
\hline Age (yr) & $46 \pm 9$ \\
Female gender & $50(43 \%)$ \\
Race & \\
White & $63(55 \%)$ \\
African-American & $42(37 \%)$ \\
Other & $10(9 \%)$ \\
Body mass index (kg/m2) & $28.0 \pm 3.7$ \\
Shift workers & $8(7 \%)$ \\
Measures of BP & \\
Screening BP (mmHg) & $140 \pm 7 / 90 \pm 5$ \\
24-hr BP (mmHg) & $132 \pm 10 / 80 \pm 8$ \\
Awake BP (mmHg) & $136 \pm 11 / 84 \pm 8$ \\
Sleep BP (mmHg) & $118 \pm 12 / 69 \pm 9$ \\
BP dip (mmHg) & $18 \pm 7 / 15 \pm 5$ \\
Systolic sleep/awake BP ratio & $0.87 \pm 0.05$ \\
Diastolic sleep/awake BP ratio & $0.82 \pm 0.06$ \\
\hline
\end{tabular}

Data expressed as $\mathrm{n}(\%)$ for categorical variables and mean $\pm \mathrm{SD}$ for continuous variables, where mean and SD pertain to the average across sessions 1,2 , and 3 for each subject

$\mathrm{BP}=$ blood pressure 
Table 2

Measures of sleep duration and quality and of daytime activity

\begin{tabular}{lcc}
\hline Characteristic & Mean \pm SD & $\begin{array}{c}\text { Average absolute } \\
\text { variation (mmHg) }\end{array}$ \\
\hline Sleep measures & & \\
Sleep time duration $(\mathrm{hr})$ & $7.6 \pm 1.0$ & $0.6(0.3-1.1)$ \\
Sleep efficiency & $82 \pm 8$ & $5.1(2.9-8.7)$ \\
Fragmentation index & $30.8 \pm 11.9$ & $9.4(7.0-14.1)$ \\
Activity measure & & \\
Awake activity (counts/min) & $233 \pm 82$ & $33(16-55)$ \\
\hline
\end{tabular}

Data express as mean $\pm \mathrm{SD}$ or median (interquartile range) 


\section{Table 3}

Reproducibility of measures of systolic blood pressure

\begin{tabular}{lccc}
\hline BP measure & $\begin{array}{c}\text { Average absolute } \\
\text { variation }\end{array}$ & $\begin{array}{c}\text { Reproducibility } \\
\text { coefficient }\end{array}$ & $\begin{array}{c}\text { Intraclass } \\
\text { correlation }\end{array}$ \\
\hline Screening BP (mmHg) & $5.3(3.3-8.0)$ & $5.7(5.2,6.3)$ & $0.56(0.46,0.66)$ \\
24-hour BP (mmHg) & $3.7(2.4-5.6)$ & $4.0(3.6,4.4)$ & $0.87(0.82,0.90)$ \\
Awake BP (mmHg) & $3.8(2.3-5.4)$ & $4.0(3.7,4.4)$ & $0.87(0.83,0.90)$ \\
Sleep BP (mmHg) & $5.2(3.3-7.6)$ & $5.9(5.4,6.5)$ & $0.78(0.72,0.84)$ \\
BP dip (mmHg) & $5.2(3.1-8.1)$ & $5.6(5.1,6.1)$ & $0.53(0.42,0.63)$ \\
Sleep/awake ratio & $0.036(0.025-0.053)$ & $0.039(0.036,0.043)$ & $0.55(0.44,0.64)$ \\
\hline
\end{tabular}

Data expressed as median (interquartile range) for average absolute variation, and value (95\% confidence interval) for reproducibility coefficient and intraclass correlation 
Table 4

Effects of sleep duration and quality and of daytime activity on systolic blood pressure dip

\begin{tabular}{lcccc}
\hline Parameter & Estimate & S.E. & $\mathbf{t}$ & $\mathbf{P}$ \\
\hline Sleep duration & & & & \\
Intercept & 26.586 & 5.098 & & \\
Mean sleep time duration & -0.505 & 0.735 & -0.69 & 0.493 \\
Daily sleep time duration & -0.618 & 0.406 & -1.52 & 0.129 \\
Fragmentation index & & & & \\
Intercept & 22.629 & 1.688 & & \\
Mean fragmentation index & -0.033 & 0.062 & -0.53 & 0.595 \\
Daily fragmentation index & -0.115 & 0.035 & -3.26 & 0.001 \\
Sleep efficiency & & & & \\
Intercept & & & & \\
Mean sleep efficiency & 0.184 & 0.093 & 1.99 & 0.048 \\
Daily sleep efficiency & 0.092 & 0.055 & 1.67 & 0.096 \\
Daytime activity & & & & \\
Intercept & 15.133 & 1.894 & & \\
Mean activity counts/min & 0.003 & 0.012 & 0.29 & 0.775 \\
Daily activity counts/min & 0.009 & 0.009 & 1.13 & 0.261 \\
\hline
\end{tabular}

